\title{
Algunos apuntes sobre Cartografía militar
}

\author{
Luis Fco. Martínez Montiel
}

Historiador del Arte

\section{Resumen}

La importancia geoestratégica de nuestra comunidad es clave en la explicación del abundante material cartográfico que de ella se conserva. Los Fondos Cartográficos de carácter militar suponen un patrimonio fundamental para el conocimiento de la evolución urbanística de muchas de nuestras ciudades. Sin embargo, la cantidad no es más que un factor, pues en realidad lo que sorprende a poco que uno se aproxime es la gran calidad y riqueza de información que estos aportan. En ambos sentidos, Andalucía puede considerarse una privilegiada en lo que a sus documentos se refiere, aunque en un porcentaje muy elevado estos no se conserven dentro del propio territorio regional. La existencia de estos fondos se pueden rastrear no sólo por toda la Comunidad Andaluza y por supuesto en toda España, sino que también es básico el uso de los archivos de instituciones extranjeras en las que se custodian importantes documentos relativos a Andalucía. Una primera aproximación a estos fondos y a su especial significación son los objetivos básicos de este artículo.

\section{Palabras Clave}

Cartografía militar / Documentos gráficos / Andalucía / Ingenieros militares / Mapas / Planos / Cartas / Dibujos / Maquetas

La importancia que, para el análisis del urbanismo español y andaluz, tienen los Fondos Cartográficos de carácter militar, quedaría explicada simplemente por la gran cantidad de documentos conservados en numerosas instituciones. Sin embargo, la cantidad no es más que un factor, pues en realidad lo que sorprende a poco que uno se aproxime es la gran calidad y riqueza de información que estos aportan. En ambos sentidos, Andalucía puede considerarse una privilegiada en lo que a sus documentos se refiere, aunque en un porcentaje muy elevado estos no se conserven dentro del propio territorio regional. Los documentos gráficos y los escritos a ellos anexos se pueden considerar como la fuente más importante para el conocimiento del urbanismo y su evolución en muchas de las ciudades andaluzas. Su importancia geoestratégica explica claramente la abundancia de material gráfico existente, de forma dispersa, en una gran cantidad de instituciones, tanto españolas como extranjeras. De nuestra región se conservan numerosos do-

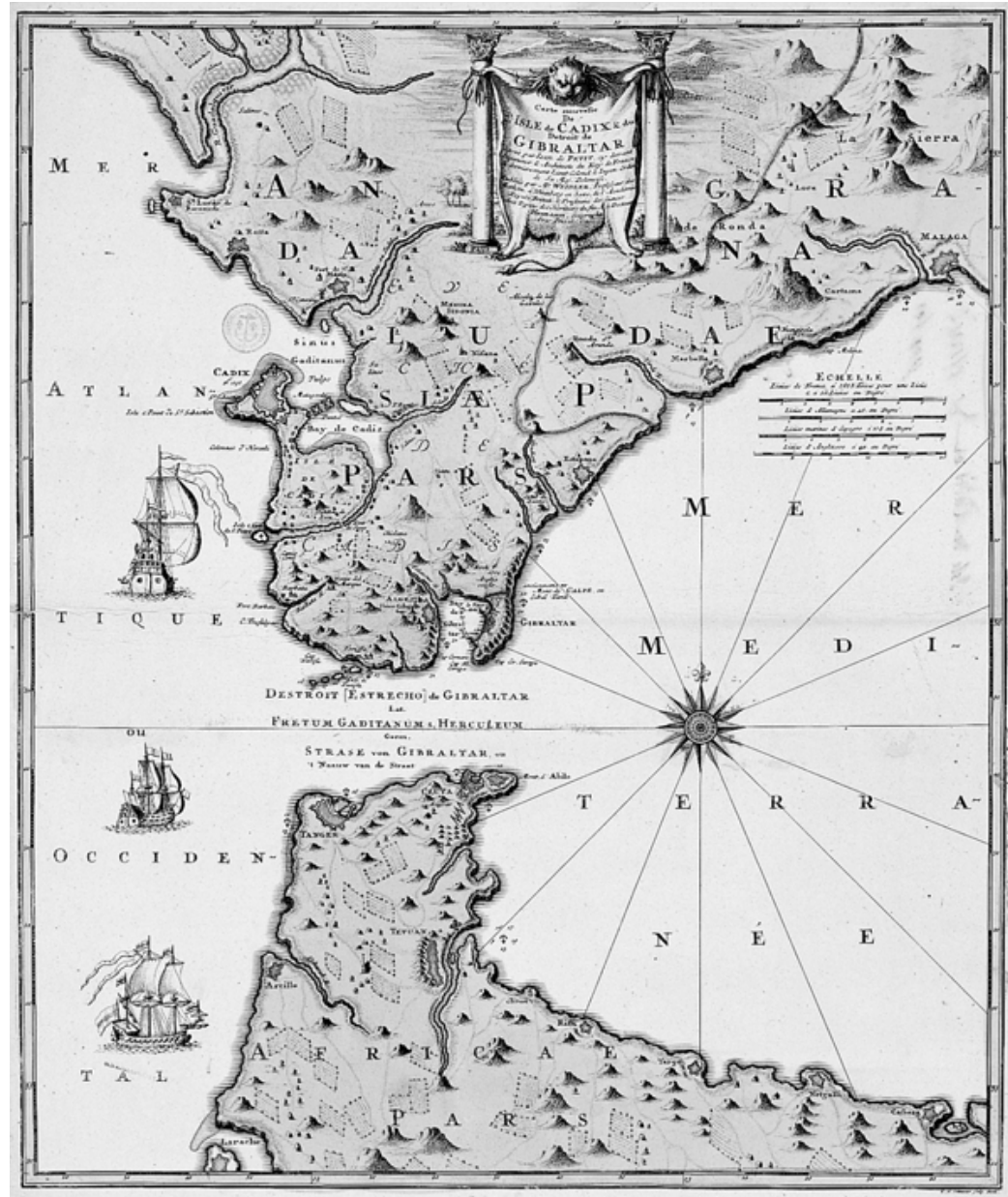

cumentos desde tiempos remotos. La importancia de ésta en los periodos clásicos de la cultura explica el que se realizaran algunos de los más conocidos. Los levantamientos, casi bosquejos, incorporados por Estrabón, o los llevados a cabo en época islámica son sólo una pequeña muestra de lo que con el discurrir del tiempo se convertirían en una inagotable fuente de conocimiento para la arquitectura y el urbanismo. Sin embargo, el auge de la cartografía y sobre todo el desarrollo a veces exhaustivo está íntimamente ligado al desarrollo y consolidación de los ejércitos y a sus necesidades de conocimiento del terreno que debían defender o atacar.

Desde la edad de oro el ejército fue realizando numerosas aproximaciones al territorio en el que se desenvolvían sus acciones. Sin embargo, los documentos conservados no sólo corresponden a los trabajos de los militares españoles, sino que, además en gran número, mucho de los trabajos fueron realizados por los ejércitos extranjeros. Un caso bien conocido es el francés. Desde el siglo XVII y hasta bien entrado el siglo $X X$ el ejército del país vecino fue recopilado a través de sus "Servicios de Información
Plano de Cádiz y del Estrecho de Gibraltar. Jean de Petit. Siglo XVII. París.

Biblioteca Nacional de Francia. $N^{\circ}$ Inv. B.N.F. / GE - SH 18 PF 62 - DIV.I - P4D 


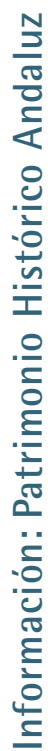

\section{Los autores}

Los primeros documentos gráficos conservados pueden atribuirse a verdaderos artistas que toma- ban sus apuntes directamente del natural. Más adelante, la especialización iba a llegar a la Cartografía que se vería notablemente desarrollada a medida que se consolidaba el Cuerpo de Ingenieros. La ingeniería militar española había empezado a formarse en el siglo XVI con súbditos italianos y flamencos que eran acompañados por ingenieros españoles que trabajaban en todos los dominios de la Corona. Sin embargo, prácticamente durante todo el siglo $\mathrm{XVII}$ los ingenieros estuvieron íntimamente relacionados con los artilleros y con la infantería, sin constituir un verdadero cuerpo independiente. Su formación no era la más adecuada y su preparación a veces no era la ideal. La mayoría de ellos habían sido elegidos entre los oficiales que tenían algún conocimiento en matemáticas y en la construcción de fortificaciones. La Academia Militar de Bruselas era la más importante a fines del siglo XVII dentro de los terrenos de la Corona. En ella se consagrarían nombres tan importantes como los de Fernández de Medrano o Cornelio Verboom, a quien sucedería su hijo Jorge Próspero Verboom. Este último será un personaje clave en la formación del Cuerpo de Ingenieros. En 1710 será nombrado Ingeniero General de los Ejércitos, Plazas y Fortificaciones de todos los Reinos, Provincias y Estados, y Cuartel Maestre General de todos los Ejércitos. Entre sus muchas funciones se le encomendaba "preparar los mapas, planos y noticias de las circunstancias, calidad y situaciones del país en que se había de hacer la guerra". Felipe $V$ expediría el 17 de abril de 17II en Zaragoza El Plan General de los Ingenieros de los Ejércitos y Plazas con el que se considera fundado como tal el Cuerpo de Ingenieros. ${ }^{2}$
Plano de Cádiz durante el ataque anglo-holandés dirigido por el Conde de Essex, en 1596. Hubert. 1596. B.N.F. / RES - GE D - 1893

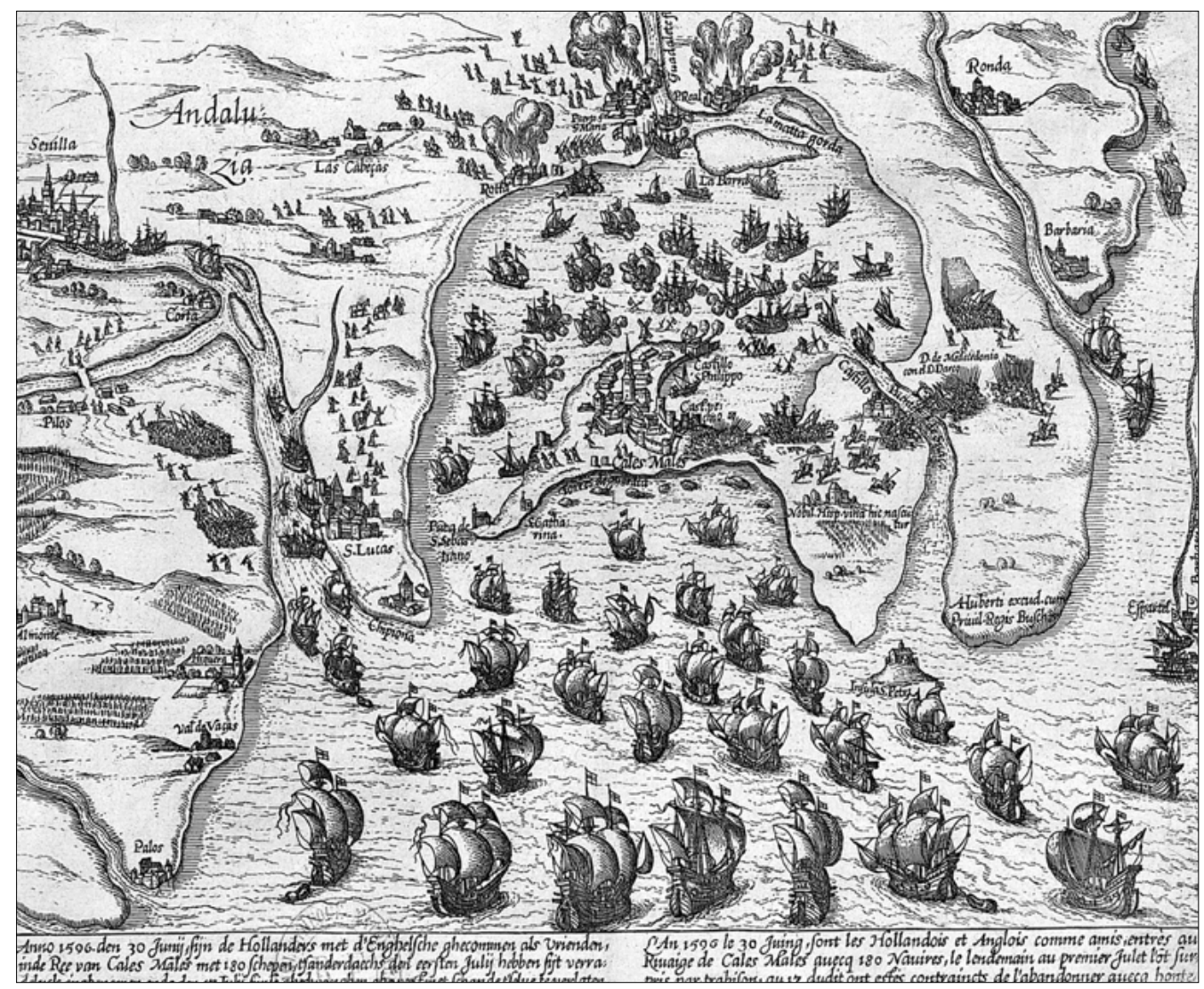




\section{Tipología}

La diversidad tipológica de los documentos gráficos conservados es considerable, aunque a veces queden, la mayor parte de ellos, encuadrados dentro del epígrafe de mapas o planos. Dejando a un lado los documentos, verdaderamente más escasos, de las épocas anteriores al Renacimiento se puede decir que desde el siglo XVI se comenzaron a realizar los mapas o cartas generales que hoy en día documentan nuestras ciudades. Esta nueva etapa cartográfica que se desarrollo con la adopción de nuevos sistemas de medición y proyección promovió el paso, como expone Bonet Correa en la obra citada, de la geodesia a la planimetría. Del territorio que rodeaba a una ciudad se podía pasar al trazado de esta $O$ al de un edificio, que quedaba en esta forma analizado y representado.

Las formas más usadas en estos primeros momentos son las vistas generales o panorámicas. Normalmente representan una visión de la ciudad tomada a una distancia prudencial desde una altura cercana a ella. En estas vistas normalmente quedaban reflejados los focos de atracción más importantes de la ciudad, convirtiéndose de esta forma en claros puntos referenciales para el conocimiento de ésta. Famosas son las vistas de algunas ciudades andaluzas representadas en los tres volúmenes del libro Civitatis Orbis Terrarum ilustrado por Georg Braun y Franz Hogenberg. Este tipo de vistas muy importantes durante los siglos XVI y XVII, quedarán parcialmente relegadas a un segundo plano, hasta que ya en el siglo XIX, con el auge del movimiento romántico se vuelvan a imponer como formas válidas para representar a la ciudad. De este periodo, previo a las vistas panorámicas que la fotografía comenzaría a producir, se conservan numerosas vistas de las ciudades andaluzas. Muchas de ellas recuperan visiones tradicionales del paisaje haciendo énfasis en lo que el extranjero quería recordar de las ciudades andaluzas. Estas vistas significaran de alguna forma la recuperación de un género como el paisaje, que no se había desarrollado en exceso en España. Es el momento en que comenzarán a aparecer imágenes que marcarán hasta la actualidad la visión exótica y romántica de nuestras ciudades.

Pero con anterioridad a esta nueva valoración de las vistas de ciudades, en el siglo XVIII se desarrollaría notablemente la cartografía topográfica. Esta se puede considerar fundamentalmente unida al cuerpo de ingenieros militares, quienes con los nuevos instrumentos iban a trabajar "in situ" y posteriormente en sus gabinetes. Junto a la reglilla y la estadia iban desarrollándose nuevos instrumentos, como el teodolito, que facilitaban las labores de medición y representación considerablemente. En este sentido se debe destacar en Andalucía la existencia de una de las instituciones pioneras en lo que a levantamientos científicos se refiere, el Real Observatorio Astronómico de San Fernando. En el Observatorio se conserva, la que probablemente sea la colección histórica más importante de instrumentos astronómicos y
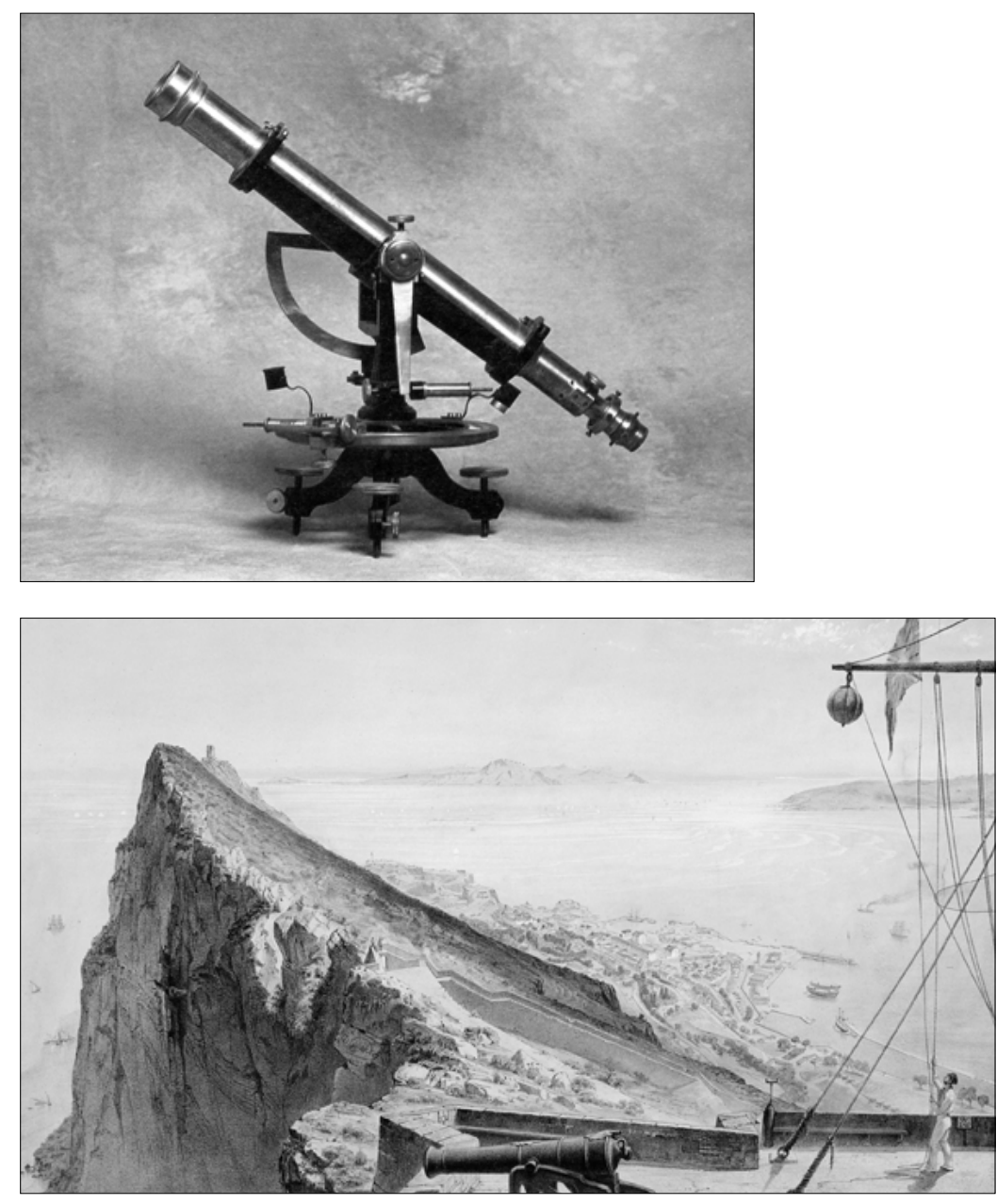

Teodolito. Ertel \& Sohn Latón, hierro y cristal. Munich. 1880.

geodésicos. Junto a estos, ya aparecen en los primeros inventarios numerosos instrumentos de dibujo y geodesia. Entre ellos merecen ser destacados los que se recogen en el inventario realizado por el teniente de navío don José Infante, maestro de artillería, quien citaba como pertenecientes a la Real Academia de Guardias Marinas y al Observatorio Astronómico los siguientes instrumentos:

Real Observatoio Astronómico de San Fernando. Cádiz. $N^{\circ} \operatorname{lnv}$. 0028/B7.

Vista del Peñón de Gibraltar.

Madrid. Museo Naval.

\begin{tabular}{|rl|}
\hline 2 & estuches matemáticos \\
\hline 2 & pantómetras \\
\hline 7 & compases \\
\hline 3 & escalas \\
\hline 5 & planchetas \\
\hline 2 & reglas \\
\hline 1 & cadena de 20 toesas \\
\hline 2 & podómetros \\
\hline 2 & chalones \\
\hline 22 & piquetes \\
\hline 2 & toesas \\
\hline 1 & vara de Burgos \\
\hline 1 & Teodolito \\
\hline 2 & reglas grandes \\
\hline 1 & estuche grabado \\
\hline 56 & cuerpos geométricos \\
\hline 1 & rombógrafo \\
\hline
\end{tabular}

Una parte importante de esta relación se conserva en el Museo del Real Observatorio Astronómico de San Fernando. Muchos de ellos serían, con toda seguridad, usados en la elaboración, por parte del Real 


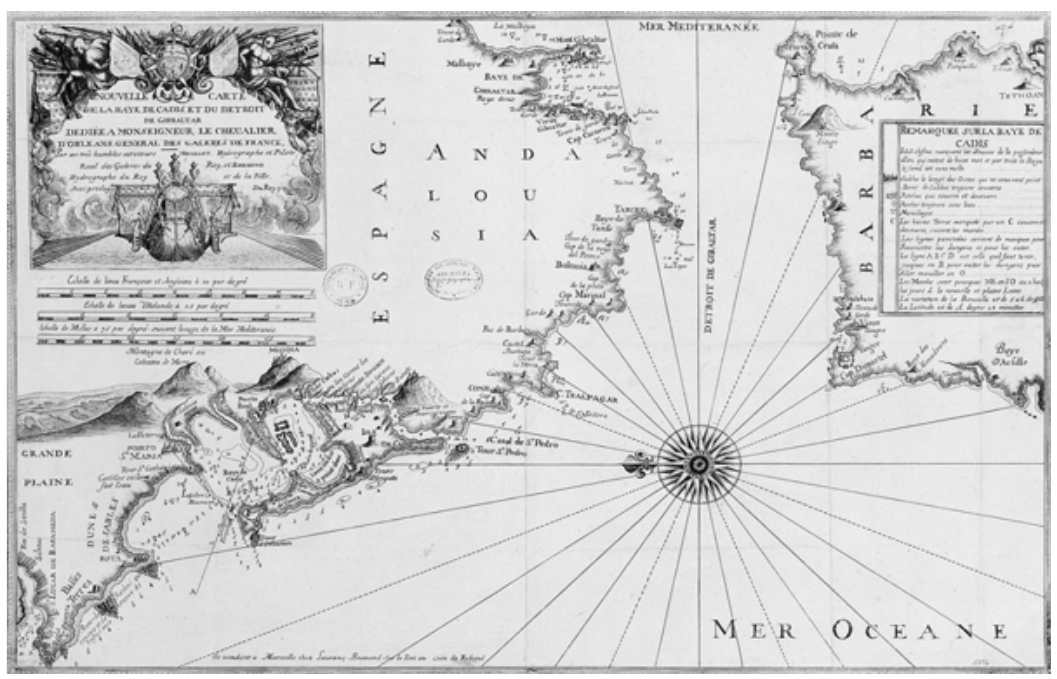

Carta de la Bahía de Cádiz y Estrecho de Gibraltar.

Michelot y Bremond. 1718. B.N.F. / GE

DD 2987 (1716) B

Detalle de la Bahía de Cádiz.

1789. Madrid.

Biblioteca Nacional. 06। B.N:M:/R/9716

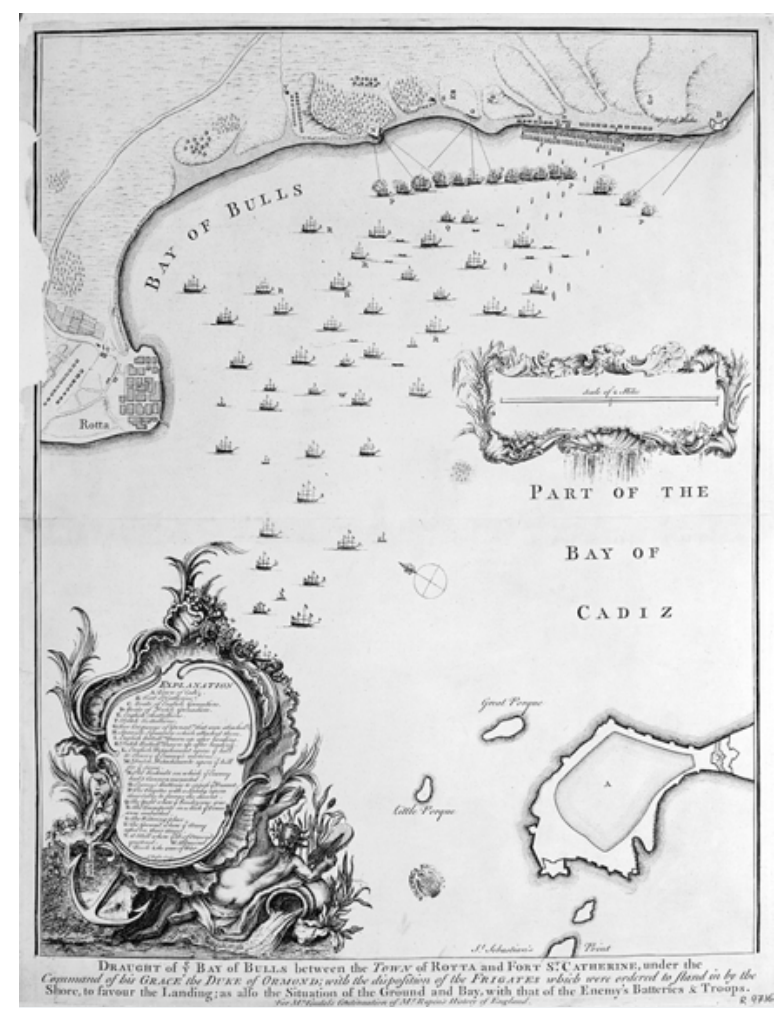

Observatorio, de la primera elaboración del mapa de España mediante el sistema de triangulación. Sistema que introducía una exactitud hasta entonces no conocida en España ${ }^{3}$. En los fondos documentales del Observatorio se conservan algunas piezas que pueden ser consideradas únicas. Tal es el caso de las Cartas Marítimas levantadas por Don Miguel Tofiño de San Miguel, que recogen la costa española y sus derroteros.

Estos avances científicos y técnicos contribuyeron al apogeo de la cartografía, que nuevamente sufriría una revolución completa con la aplicación de la Geometría Descriptiva.

A estos documentos de extraordinaria complejidad técnica que compiten en belleza con los realizados por los artistas renacentistas hay que añadir una variedad netamente diferente, la maqueta. Desde los inicios del siglo XVI el asentamiento de las Monarquías absolutas trajo consigo el desarrollo del concepto de frontera y consecuentemente la proliferación de un sistema de fortificaciones usadas como instrumentos de defensa, pues no hay que dejar a un lado el avance en las artes de la guerra. Ante la falta, en esos momentos, de un sistema cartográfico de representación especialmente riguroso, que permitiese el conocimiento exhaustivo del territorio, los ingenieros militares de la época usaron los "modelos topográficos" - maquetas como medio de análisis de las plazas fuertes que debían defender o atacar ${ }^{4}$.

En España estos modelos fueron más tardíos que en el resto de Europa. Su complejidad y costosa construcción motivaría que no fueran muy usuales. El levantamiento de estas maquetas se debe encuadrar dentro de una tendencia que si bien en otros países había comenzado con anterioridad era en estos momentos cuando realmente se había consolidado como una realidad. Francia poseía una magnííca colección de modelos de plazas fuertes potenciada por Luis XIV de las que algunas se conservan en los Inválidos en París. En España no será hasta el reinado de Carlos III cuando don Antonio Funes de Villalpando, Conde de Ricla promoviera el "Gabinete de modelos". En 1772, como Secretario de Estado y del Despacho de la Guerra disponía que se hiciese una colección de "bajorrelieves o modelos de todas las plazas y fortificaciones de España y sus adyacentes capaces de defensa". Responsable junto a Funes de Villalpando de este proyecto fue Francisco de Sabatini, quien era ya director general del Cuerpo de Ingenieros.

El proyecto preveía que se comenzará a trabajar según un Reglamento aprobado el 16 de abril de 1777. Nacía con una dotación de 6000 escudos, que debían invertirse por el interés de la plaza en la construcción de la "maqueta de Cádiz" y en los presidios menores. El encargo se le hacía a Alfonso Jiménez, quien comenzaba a trabajar ese mismo año, en la que a la postre sería la única maqueta realizada para satisfacer los deseos del Conde de Ricla. El esforzado trabajo en la realización de la maqueta gaditana queda recogido en un interesante legajo conservado en el Archivo General de Simancas ${ }^{5}$. En el se nos informa de todo el desarrollo del proyecto, incluyendo los pormenores de su construcción. Especialmente interesante parece el apartado en el que su autor describe como lleva a cabo la labor: "...he travajado las cosas mas menudas a el ausilio de su mayor estencion. A lo que he continuado cortando una infinidad de perfiles y elevaciones y en donde esto no ha sido suficiente he procedido a la copia del terreno en zera y otros borrones que aumenta la perfección que deseo... en sus flancos, alturas, comunicaciones, quarteles, poternas, agibes y pavellones no escuso diferencia de un pie ni el punto mas minimo de su original". El deseo del parecido con la realidad era evidente y así llegó a construir probablemente una de las piezas más emblemáticas del patrimonio gaditano, su maqueta. Esta, de gran- 


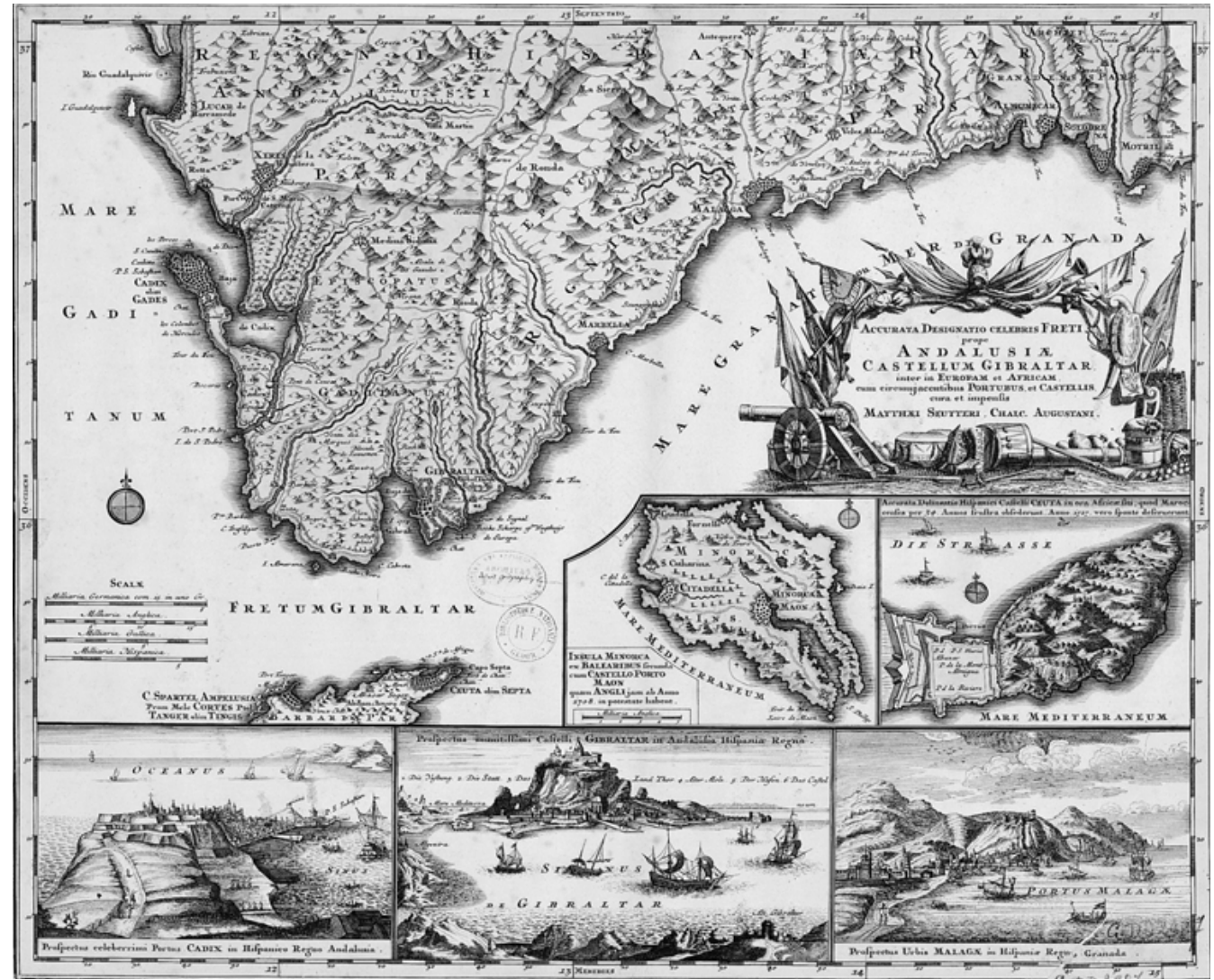

Plano de la costa andaluza desde el Guadalquivir hasta Motril. 1727. París. Biblioteca Nacional de Francia. $N^{\circ}$ Inv. B.N.F. / GE - DD 2987 (1710).

Granada. Plano de la ciudad y alrededores. $|8| 0-|8| \mid$ Archives du Genie. Castillo de Vincennes. París.

des proporciones, se encuentra actualmente expuesta en el Museo Histórico Municipal de Cádiz, donde actualmente está siendo restaurada 6 .

\section{Las claves}

La variedad de propuestas que recogen cada uno de estos documentos gráficos hace prácticamente imposible la normalización de su estudio. Desde los borradores, apenas unas líneas claves para situar los elementos más destacados, hasta la sofisticación de un gran plano de fines del siglo XVIII o principios del siglo XIX, existe todo un mundo de posibilidades. Acompañando al elemento gráfico representacional del territorio, ciudad, o edificio normalmente suelen aparecer una serie de elementos que junto al documento textual, que normalmente se anexaba, explicaba el porque de su realización dando las claves para su interpretación. La elaboración de algunos de ellos resulta prácticamente impensable en la actualidad, pues como el especial grafismo que acompaña al plano eran elementos íntimamente ligado al momento que originó el documento. Especial relevancia tienen, en este sentido, las cartelas. El lugar donde normalmente se titulaba el plano, se especificaba su escala y en ocasiones se explicaba el motivo de su confección, a quien estaba dedicado y otra serie de circunstancias que rodeaban su creación.

A la leyenda, la explicación de lo representado con todo tipo de aclaraciones se le dedicaba otra parte fun-

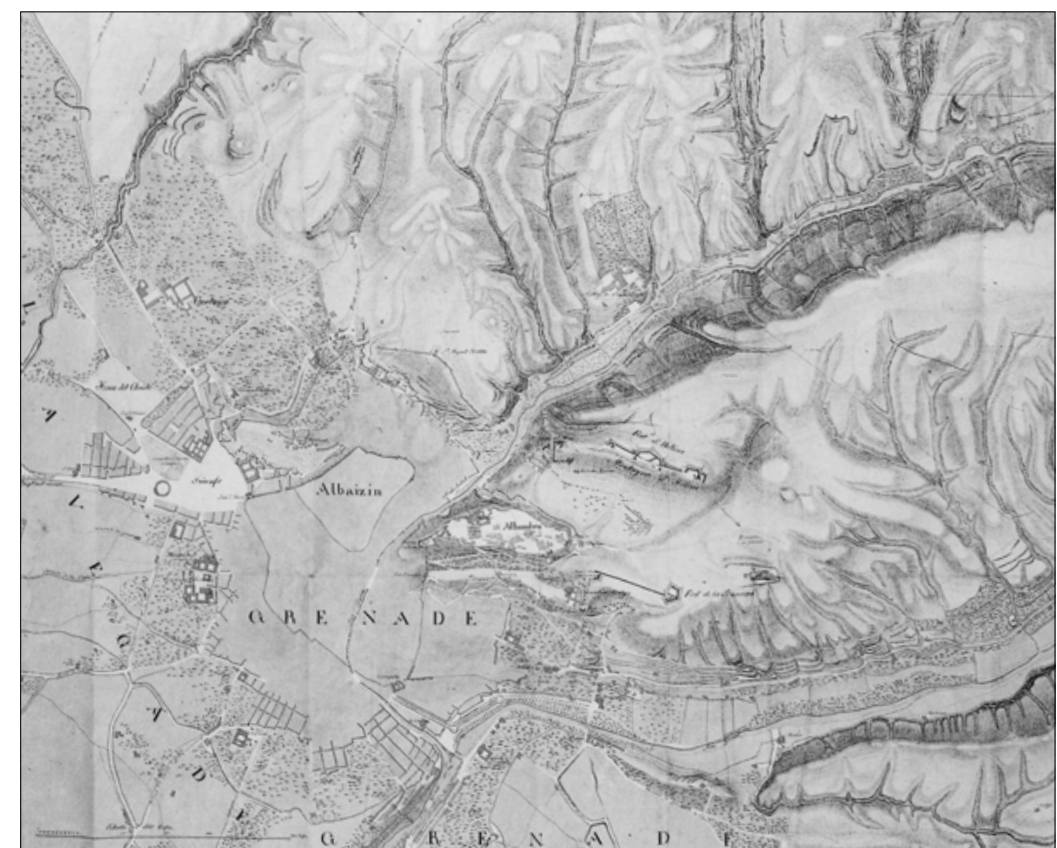

damental de éste. Desde las prolijas descripciones en las que prácticamente se narra el devenir del territorio hasta las más sintéticas, que se limitan a subrayar, a veces lo evidente existe toda una gama de posibilidades.

Especialmente interesante para el estudio del documento es el pie del plano. En el, con más frecuencia de lo pensado, incluso se llega a exponer no sólo el 


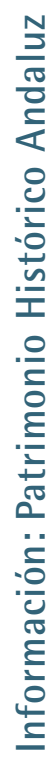

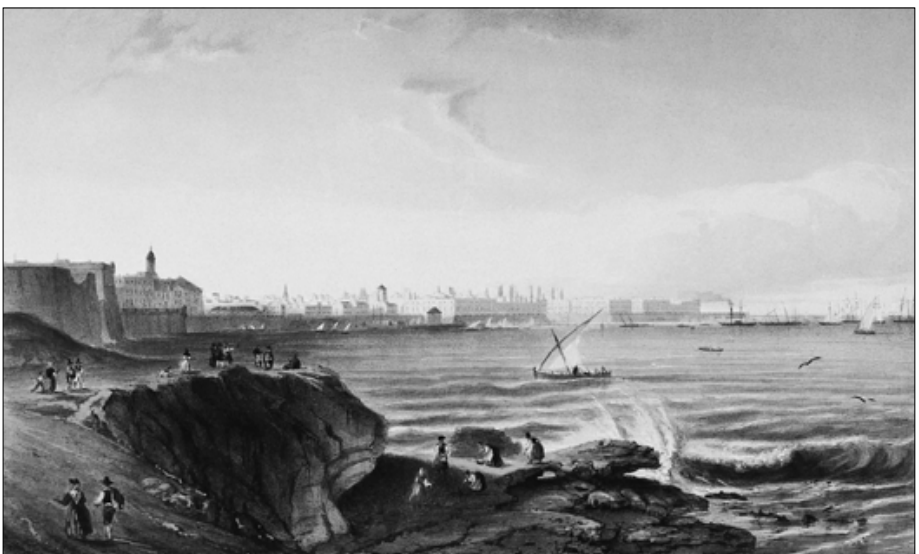

Vista de Cádiz.

Madrid.

Museo Naval. Inv. 3616.

autor del dibujo o el grabador, sino también el editor y a veces el lugar en el cual podía ser comprado. Lo que en un principio podía ser tenido como un instrumento militar de trabajo, se convertía a veces en una guía para viajeros.

La forma de representar también son identificativas del documento pues los énfasis se sitúan en diferentes lugares dependiendo del tipo de documento confeccionado. Así es muy interesante observar para una misma zona, las grandes diferencias representacionales entre una Carta Marítima y su correspondiente mapa. La minuciosidad con la que es delineada la costa en la primera y el énfasis que se pone en los grandes hitos, necesarios para orientar la navegación, contrasta con la aparente torpeza de las delineaciones con las que se construyen las costas en una mapa terrestre, incluso a veces bien avanzado el siglo XVIII. Mientras que en el mapa del territorio, las curvas de nivel, de las diferentes elevaciones, quedan perfectamente definidas, incluso situando esquemáticamente las poblaciones, en las cartas apenas son recogidas y en sus derroteros, alzados de las costas, tan sólo son marcados las mayores alturas que funcionaran como referencias para el tránsito marítimo.

\section{Las instituciones}

La relación de instituciones en las que se conservan documentos gráficos sería prolija de realizar y aun así estaría encaminada al fracaso, pues no es extraño que esporádicamente se descubran nuevos documentos que habían permanecido en el olvido, o no valorados hasta esos momentos. Con la profunda remodelación que se está llevando a cabo en las Fuerzas Armadas a nivel estatal, en Andalucía numerosas ciudades están comprobando como sus instituciones militares están perdiendo peso específico en el desarrollo de las ciudades en las que se asien$\tan , y$ en las que hasta no hace mucho eran referencias claras. Ello está produciendo, que a la vez que se producen pérdidas de todo tipo para las ciudades, pérdidas que van desde las de carácter económico hasta las de ámbito social o cultural, se puedan producir salidas de documentación, fundamental para el conocimiento de la evolución arquitectónica y urbanística de ellas. Las concentraciones de instituciones militares y las cesiones o ventas de algunos edificios de gran trascendencia pueden suponer la pérdida de una información importantísima. Muchos municipios andaluces poseen en sus Archivos, militares o civiles, numerosos documentos gráficos, realizados en muchos casos por los técnicos militares que son de vital importancia para el conocimiento de la ciudad. Idéntica situación ocurre en las capitales de provincia y sobre todo en aquellas que fueron sedes de Capitanías Generales o Gobiernos Militares en los que hasta no hace mucho se conservaban numerosísimos documentos. En muchos casos estos han sido enviados a los servicios centrales, donde afortunadamente una vez inventariados podrán ser usados por el investigador.

No es este el lugar para descubrir los grandes Archivos Militares en los que estos documentos son conservados. A ellos se puede acceder fácilmente, incluso a veces a través de internet como más adelante se verá. Tan sólo mencionar algunos que podrí-
Monumentos y conjuntos de la costa. Archives du Genie. Castillo de Vincennes. París.

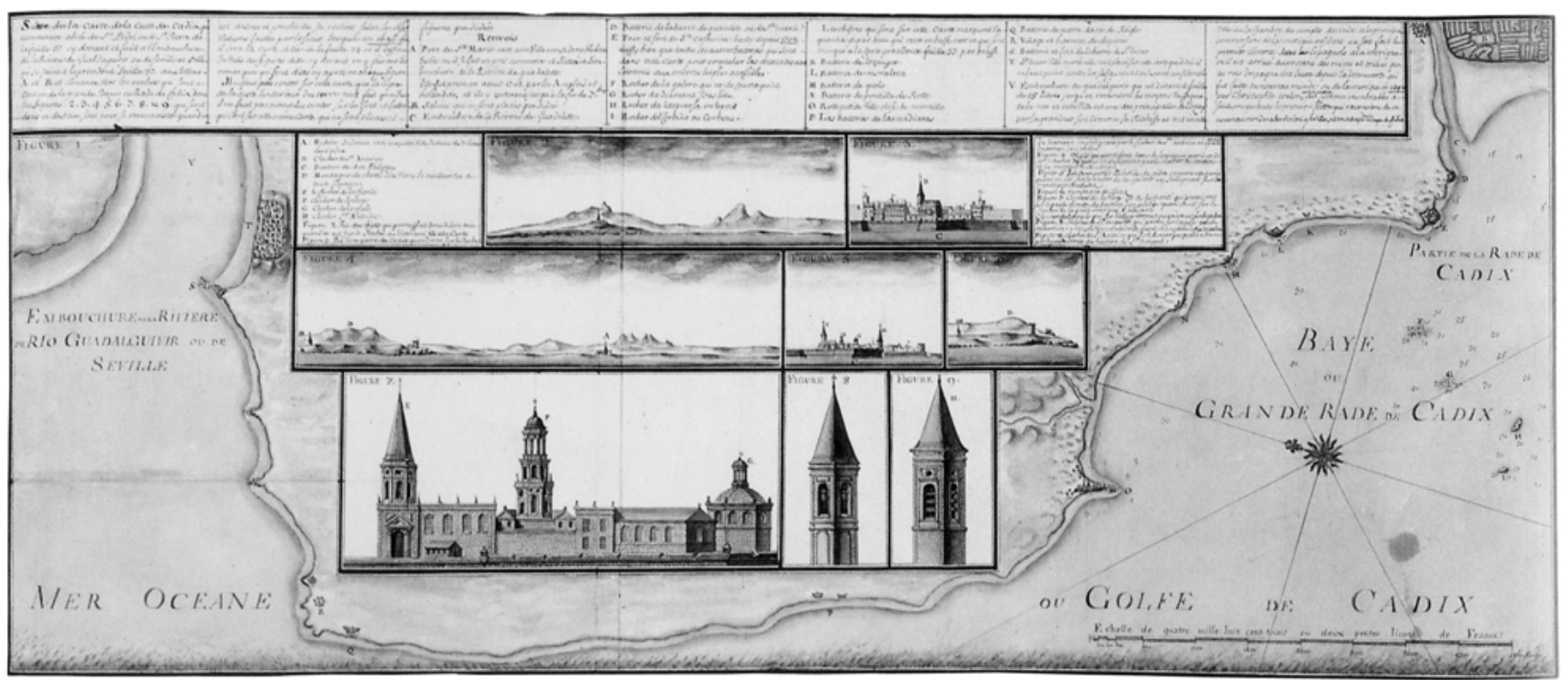


an ser menos conocidos, como los casos del Instituto Hidrográfico de la Marina en Cádiz, el ya citado Real Observatorio Astronómico de San Fernando, ambos con una interesantísima documentación gráfica desde el siglo XVIII o el Museo del Ejército de la Capitanía General de Sevilla, con una colección francamente impresionante de planimetría que abarca desde el siglo XVIII hasta el XX. A nivel nacional además de los archiconocidos Servicio Geográfico del Ejército o el Archivo Histórico Militar es muy interesante la documentación custodiada en el Museo Naval de Madrid o en el propio Archivo General de Simancas, donde las secciones de Guerra y Marina son básicas, sobre todo en su colección de Mapas, Planos y Dibujos.

Más complejo resulta imaginar que documentación gráfica militar española se encuentre depositada en instituciones extranjeras. Sin embargo, como ya se planteó al inicio de este escrito, los Servicios de Inteligencia extranjeros, bien realizándolos "in situ" o bien copiándolos de otros anteriores realizados por españoles se hicieron con una documentación fundamental para conocer un gran número de ciudades españolas y andaluzas en particular. Especialmente interesantes son los documentos conservados en Francia, donde dos instituciones el "Archive du Genie" en el Castillo de Vincennes y la Biblioteca Nacional de Francia, ambas en París, asombran por la cantidad y calidad de ellos. Los fondos españoles del primero fueron estudiados y analizados por el profesor Bonet Correa. Los de la Biblioteca Nacional de Francia han sido parcialmente analizados en diferentes publicaciones 7. Asimismo, en Inglaterra son muy interesantes y prácticamente inéditos los conservados en la "British Library" y en el espectacular Gabinete de Grabados y Dibujos del "Victoria and Albert Museum", ambos en Londres.
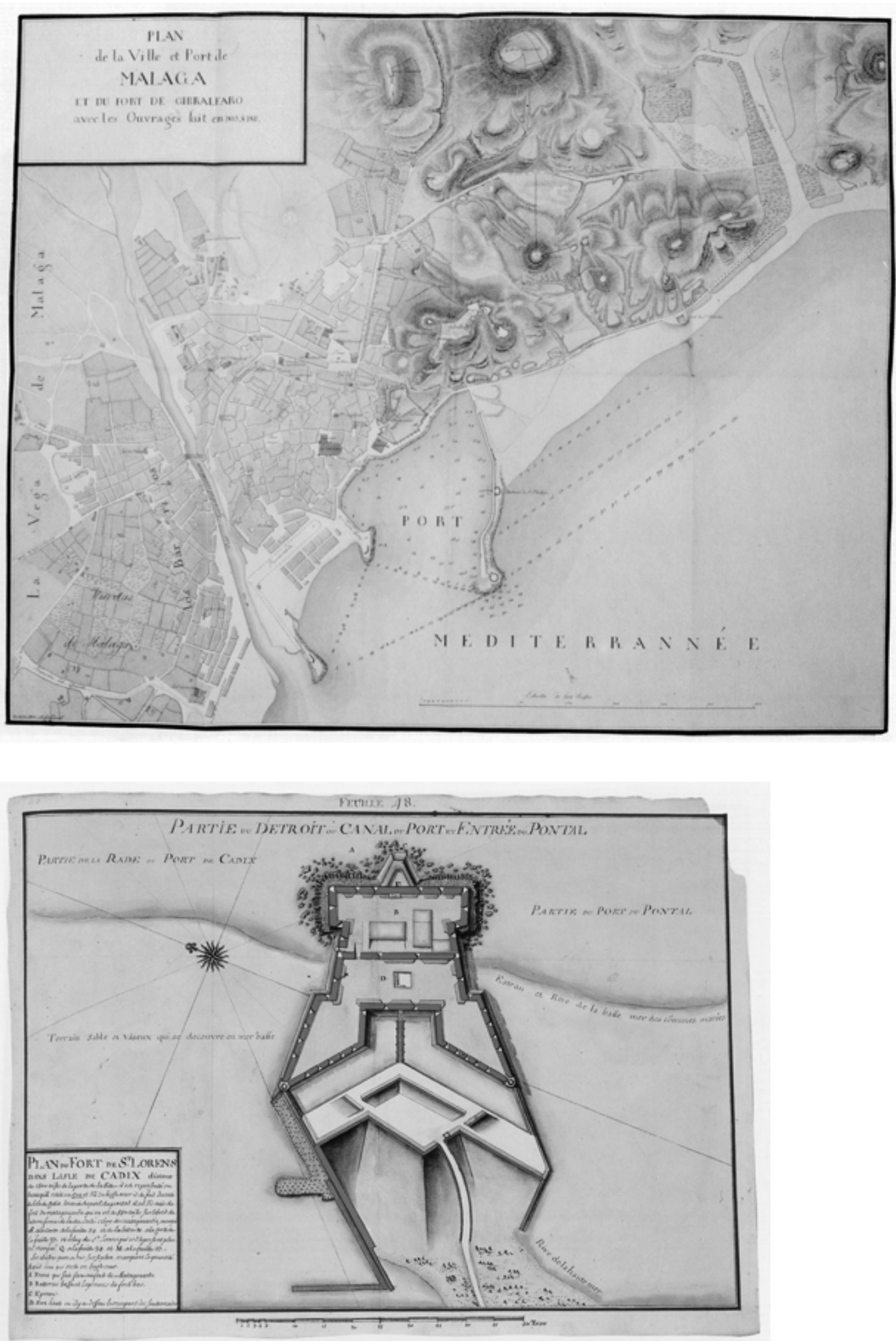

Málaga. Plano de la ciudad y Gibralfaro. |8|0-|8||. Archives du Genie. Castillo de Vincennes. París.

Cádiz. Fuerte de San Lorenzo. Archives du Genie. Castillo de Vincennes. París.
I. Al respecto se debe consultar de BONET CORREA, Antonio: Cartografía militar de Plazas Fuertes y Ciudades Españolas. Siglos XVII-XIX. Planos del Archivo Militar Francés. Madrid. Instituto de Conservación y Restauración de Bienes Culturales. 1991.

2. Sobre la creación del Cuerpo de Ingenieros existen numerosos estudios. Especialmente interesante son de CAPEL, Horacio et alii: De Palas a Minerva. La formación científica y la estructura institucional de los ingenieros militares en el siglo XVIII. Serbal / CSIC. Barcelona, 1988

3. Sobre la gran colección de instrumentos conservadas en el Real Observatorio Astronómico se debe consultar a GONZÁLEZ GONZÁLEZ, Francisco losé: Instrumentos Científicos del Observatorio de San Fernando (Siglos XVIII, XIX y XX). Madrid. Ministerio de Defensa. 1995.

4. Sobre los "modelos topográficos" es necesario consultar a QUIROS LINARES, Francisco: "Las colecciones militares de modelos de ciudades españolas, y el Real Gabinete Topográfico de Fernando VII. Una aproximación". En Eria. Revista de Geografía. Número 35. Págs. 203-224. Oviedo. 1994.
5. El Legajo citado se encuentra en el Archivo General de Simancas. Sección de Guerra Moderna. Legajo 3807.

6. Sobre la construcción de la maqueta gaditana y sobre los detalles que la rodearon pueden consultarse, además del artículo citado de Quiros Linares, el de MARTíNEZ MONTIEL, Luis F.: "La maqueta de Cádiz, algunos apuntes sobre la construcción y su autor". En Laboratorio de Arte. Número 12. Págs. 279-291. Sevilla, 1999.

7. Sobre el Archive du Genie en París véase el libro citado en la nota I. Por lo que respecta a los fondos de la Biblioteca Nacional de Francia, los referentes a la provincia de Cádiz fueron estudiados por CALDERÓN QUIIANO, I.A. et alii en: Cartografía Militar y Marítima de Cádiz. 1513-1878. Escuela de Estudios Hispano Americanos. Sevilla, 1978. Y en BARROS CANEDA, J.R. y MARTíNEZ MONTIEL, L.F. Más allá de las columnas de Hércules. Cartas, Mapas, Planos y Dibujos desde 1513 a 1823. Grupo Información. Jerez de la Frontera, 1999. 